\title{
Physical-chemical characteristics of an eco-friendly binder using ternary mixture of industrial wastes
}

\author{
Hoang-Anh Nguyen, Ta-Peng Chang $\bowtie$, Chun-Tao Chen, Tzong-Ruey Yang, Tien-Dung Nguyen \\ National Taiwan University of Science and Technology (NTUST) (Taiwan Tech), (Taipei, Taiwan) \\ $\triangle$ tpchang@mail.ntust.edu.tw
}

Received 21 October 2014

Accepted 27 February 2015

Available on line 22 July 2015

\begin{abstract}
This study explores the physical-chemical characteristics of paste and mortar with an eco-friendly binder named as SFC cement, produced by a ternary mixture of industrial waste materials of ground granulated blast furnace slag (S), Class F fly ash (FFA), and circulating fluidized bed combustion fly ash (CFA). To trigger the hydration, the CFA, which acted as an alkaline-sulfate activator, was added to the blended mixture of slag and FFA. The water to binder ratio (W/B), curing regime, and FFA addition significantly affected the engineering performances and shrinkage/expansion of the SFC pastes and mortars. The SFC mortars had higher workability than that of ordinary Portland cement (OPC). With similar workability, the SFC mortars had compressive strengths and expansions comparable to OPC mortars. The main hydration products of the hardened $\mathrm{SFC}$ cement were ettringite $(\mathrm{AFt})$ and $\mathrm{C}-\mathrm{S}-\mathrm{H} / \mathrm{C}-\mathrm{A}-\mathrm{S}-\mathrm{H}$. The transformation of the $\mathrm{AFt}$ to the monosulfates was observed as the hydration time increased.
\end{abstract}

KEYWORDS: Fly ash; Blast furnace slag; Cement paste; Mortar; Hydration products

Citation/Citar como: Hoang-Anh Nguyen; Ta-Peng Chang; Chun-Tao Chen; Tzong-RueyYang; Tien-Dung Nguyen (2015) Physical-Chemical Characteristics of an Eco-Friendly Binder Using Ternary Mixture of Industrial Wastes. Mater. Construcc. 65 [319], e064. http://dx.doi.org/10.3989/mc.2015.07414.

RESUMEN: Características fisicoquímicas de un ligante eco-amigable usando una mezcla ternaria de residuos industriales. Este trabajo estudia las características fisicoquímicas de pastas y morteros con un ligante ecoamigable llamado cemento SFC, producido por una mezcla ternaria de materiales a partir de residuos industriales tales como escorias granuladas de alto horno (S), ceniza volante clase F (FFA), y cenizas volantes de combustión en lecho fluidizado circulante (CFA). Para desencadenar la hidratación, el CFA que actuó como un activador alcalino-sulfato se añadió a la mezcla combinada de escoria y FFA. La relación de agua/ligante (W/B), el tipo de curado, y la adición de FFA afectaron significativamente a las prestaciones mecánicas así como a la retracción/expansión de pastas y morteros de SFC. Los morteros SFC presentaron una trabajabilidad mayor que los correspondientes de cemento de Portland (OPC). Con una trabajabilidad similar, los morteros SFC presentaron resistencias mecánicas y expansión comparables a los morteros de OPC. Los principales productos de hidratación del cemento SFC fueron etringita (AFt) y geles C-S-H/C-A-S-H. La transformación de AFt a mono sulfatos fue observada a medida que el tiempo de hidratación progresaba.

PALABRAS CLAVE: Ceniza volante; Escorias granuladas de horno alto; Pasta de cemento; Mortero; Productos de hidratación

Copyright: (C) 2015 CSIC. This is an open-access article distributed under the terms of the Creative Commons Attribution-Non Commercial (by-nc) Spain 3.0 License. 


\section{INTRODUCTION}

The power generation from the pulverized coal combustion has raised the issues on environmental pollution and climate change. To minimize these impacts, a new combustion method so-called the circulating fluidized bed combustion (CFBC) process is preferred because it not only reduces the $\mathrm{SO}_{2}$ and $\mathrm{NO}_{\mathrm{x}}$ emission during the combustion process but also significantly improves the efficiency of burning $(1,2)$. By incorporating the calcium rich raw materials (such as limestone or dolomite) as absorbents during the burning process, most of the $\mathrm{SO}_{2}$ in the CFBC process is eliminated by the reaction between $\mathrm{SO}_{2}$ and $\mathrm{CaO}$. Therefore, anhydrous anhydrite $\left(\mathrm{CaSO}_{4}\right)$ is formed in the CFBC ashes. To increase the $\mathrm{SO}_{2}$ absorption, the weight ratio of $\mathrm{CaO}$ (in absorbent) to $\mathrm{SO}_{2}$ (in raw materials) is increased and the temperature is lowered (3). The CFBC combustion technique results in the CFBC ashes with physicochemical properties different from the conventional coal fly ashes. Generally, the high free lime (f-CaO) from the unreacted absorbent and the anhydrite $\left(\mathrm{CaSO}_{4}\right)$ limit the utilization of CFBC ashes due to the expansion induced by ettringite (AFt) formation (3). Therefore, $\mathrm{CFBC}$ ashes significantly contribute to the annually increased solid wastes with sulfur, possibly leading to the pollutions in the air due to the ashes and on surface water due to the high alkalis.

The utilization of the sulfur rich solid wastes in cement/concrete industry has been the most efficient way to mitigate the aforementioned impacts because the dual benefits, i.e., both the carbon footprint of concrete and the cost of sulfate rich hydraulic cement (SC), as an alternative to the ordinary Portland cement (OPC), are reduced. Although the utilization of the by-product cementitious materials such as ground granulated blast furnace slag (GGBFS) from the iron and steel industry and pozzolans such as fly ash from the electricity generation as the complementary cementitious materials or alkaline activated materials have been established (4-15), the $100 \%$ by-product pozzolan based SCs are preferred in manufacture of eco-cement because they are cheap and environmentally friendly. Generally, the combinations of the sulfur rich materials and GGBFS and/or the natural or by-product pozzolanic materials lead to the cementing process including the dissolution and condensation of the ingredients (16-23). Now, the SCs, particularly those produced by the sulfur rich solid wastes such as $\mathrm{CFBC}$ ash and flue gas desulfurization gypsum (FDG), have been the research interest because they meet the economic and ecological requirements and have acceptable mechanical and durability properties (24-27). However, the challenge of making the SCs with reduced cost and increased mechanical quality and limited investigations on their long-term shrinkage/expansion have narrowed the application of such SCs $(26,28)$.

In this study, an eco-friendly binder named as SFC cement, produced by a ternary waste mixture of industrial waste materials of ground granulated blast furnace slag (hereafter called slag and abbreviated as S), Class F fly ash (FFA) from coal-fired power plant and circulating fluidized bed combustion fly ash (CFA), was used to produce high performance pastes and mortars with high workability, high engineering properties, and satisfactory shrinkage/ expansion. The microstructural examination was conducted to understand the hydration mechanism of such SFC cement. By using FFA to replace slag in the ternary mixture, the cost of SFC cement is significantly reduced. The low heat evolution during the cementitious hydration of slag and pozzolanic reaction of FFA in the SFC cement will overcome the issues on internal hydration heat release of the mass concretes/mortars using the OPC. Also, the results of this investigation can extend the usage of CFA to other kinds of applications in addition to using as the activator (25).

\section{EXPERIMENTAL PROGRAM}

\subsection{Materials and mix proportions}

The Type I ordinary Portland cement (OPC) in accordance with ASTM C150 (29) was used as the control reference. The Class F fly ash (FFA), slag, and CFBC fly ash (CFA) were used to produce the SFC cement. The physical properties and the chemical and mineral compositions of these byproduct materials, examined by Lab-X3500 X-ray fluorescence (XRF) on powder and BRUKER, D2 PHASER-X-Ray Diffractometer X-ray powder diffraction (XRD), are shown in Table 1 and Figure 1, respectively. The CFA contains $\mathrm{CaO}$ and $\mathrm{SO}_{3}$ while

TABLE 1. Physical properties and chemical compositions of three industrial waste materials

\begin{tabular}{|c|c|c|c|}
\hline & $\begin{array}{c}\text { GGBF } \\
\text { Slag (slag) }\end{array}$ & $\begin{array}{l}\text { Class F fly } \\
\text { ash (FFA) }\end{array}$ & $\begin{array}{l}\text { CFBC fly } \\
\text { ash (CFA) }\end{array}$ \\
\hline Specific gravity & 2.90 & 2.08 & 2.70 \\
\hline Blaine fineness, $\mathrm{cm}^{2} / \mathrm{g}$ & 6000.00 & - & 3000.00 \\
\hline $\mathrm{SiO}_{2}$, wt. $\%$ & 34.90 & 61.12 & 5.22 \\
\hline $\mathrm{Al}_{2} \mathrm{O}_{3}$, wt. $\%$ & 13.53 & 24.31 & 2.21 \\
\hline $\mathrm{Fe}_{2} \mathrm{O}_{3}$, wt. $\%$ & 0.52 & 4.26 & 0.58 \\
\hline $\mathrm{CaO}$, wt. $\%$ & 41.47 & 4.65 & 56.80 \\
\hline $\mathrm{MgO}, \mathrm{wt} . \%$ & 7.18 & 1.15 & 2.06 \\
\hline $\mathrm{SO}_{3}$, wt. $\%$ & 1.74 & - & 32.40 \\
\hline $\mathrm{K}_{2} \mathrm{O}$, wt. $\%$ & - & 0.33 & - \\
\hline $\mathrm{TiO}_{2}$, wt. $\%$ & - & 1.48 & - \\
\hline L.O.I, wt. \% & 4.72 & 2.70 & - \\
\hline
\end{tabular}




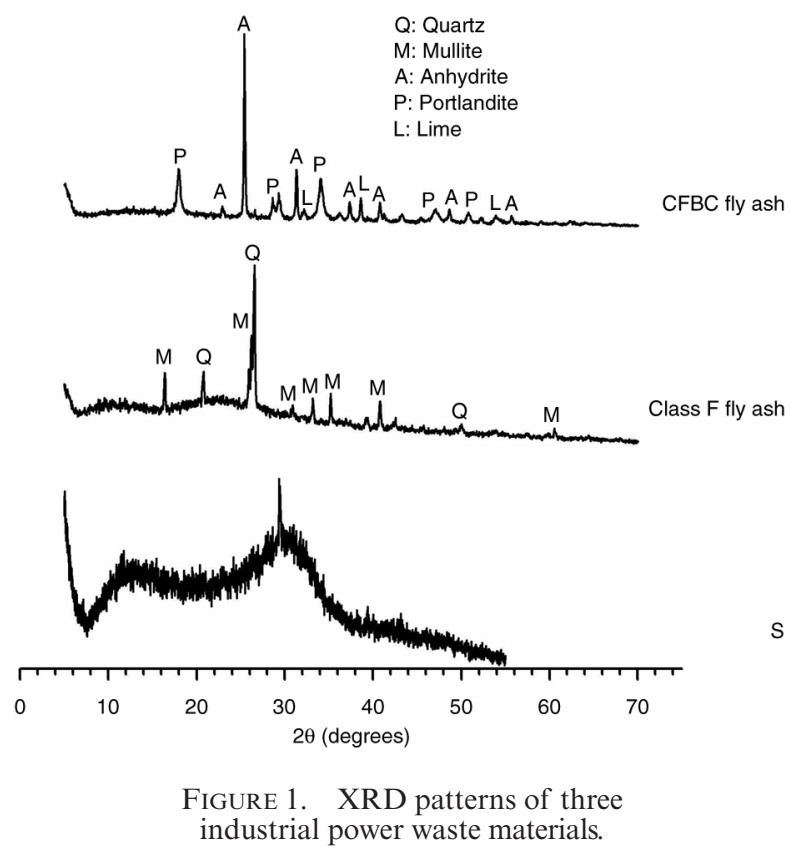

the FFA contains $\mathrm{SiO}_{2}$ and $\mathrm{Al}_{2} \mathrm{O}_{3}$. The FFA comprises mullite and quartz, and the CFA comprises portlandite, anhydrite, and lime resulted from the reaction between $\mathrm{f}-\mathrm{CaO}$ and vaporized water in the air. In contrast to FFA and CFA, the slag comprises mostly amorphous $\mathrm{CaO}, \mathrm{SiO}_{2}, \mathrm{Al}_{2} \mathrm{O}_{3}$, and $\mathrm{MgO}$ (Table 1 and Figure 1). The non-crystalline phases make the slag with alkaline and sulfate activator more active than FFA. To produce mortars, the natural river sand with the fineness modulus (FM) of 2.9 and the specific density of 2.65 was used. The water absorption of sand was $0.8 \mathrm{wt} . \%$.

In this investigation, the CFA with 15 wt. $\%$ of blended mixture of FFA and slag was used to trigger the hydration. Such amount of CFA is equivalent to $4.23 \mathrm{wt} . \% \mathrm{SO}_{3}$, being smaller than the threshold value of $4.48 \mathrm{wt} . \%$ for cement with good soundness, as suggested by some authors (30). Because 4.23 wt. $\%$ of $\mathrm{SO}_{3}$ was higher than the threshold value of $3.5 \mathrm{wt} . \%$ in expansion-controlled cement, as suggested by some other researchers (31), the volume stability in terms of the shrinkage/expansion of mortars with different curing regimes was specifically assessed in this study. The FFA, as partial replacement for slag by 10,30 , and $50 \mathrm{wt} . \%$, was used to produce SFC cement to cut the cost. Three water to binder ratios (W/B) such as $0.3,0.35$, and 0.4 for mortars were used. In addition, the SFC cement pastes with W/B of 0.35 were also used to estimate the effect of FFA on shrinkage/expansion of paste specimens. The ratio of sand to OPC or ternary blended mixture of slag, FFA, and CFA was fixed at 2.5 by weight in all mortar mixes. In this study, the slump flow of mortars was maintained at $195 \pm 5 \mathrm{~mm}$ by using different amounts of Type $\mathrm{G}$
TABLE 2. Mix proportions of SFC and OPC pastes and mortar

\begin{tabular}{|c|c|c|c|c|c|c|}
\hline & OPC & slag & FFA & CFA & Water & SP \\
\hline Mix & g & g & g & g & g & wt. $\%$ \\
\hline F10C15L30 & - & 900 & 100 & 150 & 345.0 & 0.32 \\
\hline F10C15L35 & - & 900 & 100 & 150 & 402.5 & 0.30 \\
\hline F10C15L40 & - & 900 & 100 & 150 & 460.0 & 0.14 \\
\hline F30C15L35 & - & 700 & 300 & 150 & 402.5 & 0.30 \\
\hline F50C15L35 & - & 500 & 500 & 150 & 402.5 & 0.29 \\
\hline OPCL30 & 1000 & - & - & - & 300.0 & 0.60 \\
\hline OPCL35 & 1000 & - & - & - & 350.0 & 0.30 \\
\hline OPCL40 & 1000 & - & - & - & 400.0 & 0.16 \\
\hline
\end{tabular}

Note: All the SFC and OPC mortar specimens were cast based on the weight ratio of sand to OPC or ternary blended mixture of slag, FFA, and CFA of 2.5 .

superplasticizer (SP), a high-range water-reducing admixture. The mix proportions of pastes and mortars are shown in Table 2. In Table 2, the characters $\mathrm{F}, \mathrm{C}$, and $\mathrm{L}$ for designations of mixes refer to FFA, CFA, and liquid, and the numbers following the characters are the percentage of the materials, respectively. For example, the mix designation denoted by F10C15L35 means that the mix was prepared by FFA/slag $=10 \% / 90 \%, 15 \mathrm{wt} . \% \mathrm{CFA}$ of blended mixture of FFA and slag, and $\mathrm{W} / \mathrm{B}=0.35$, respectively. The amount of SP was expressed by the percentage of the weight of total solid powder.

\subsection{Casting of specimens and test methods}

The fresh mortars were tested for the workability by the flow Table test in accordance with ASTM C1437 (32). The cubic specimens with dimensions of $50 \times 50 \times 50 \mathrm{~mm}$ were cast for the compressive strength test immediately after the workability test. For the shrinkage/expansion test, the prismatic specimens of mortars with dimensions of $25 \times 25 \times 185 \mathrm{~mm}$ were cast. After 24 hours, the specimens were removed from the molds and cured in different conditions to estimate the effects of curing regimes on the compressive strengths and shrinkage/ expansion of the SFC mortars. Three regimes of curing conditions including (1) curing in air at $27 \pm 2{ }^{\circ} \mathrm{C}, 65 \% \mathrm{RH}(\mathrm{A}),(2)$ curing in saturated lime water at $27 \pm 2{ }^{\circ} \mathrm{C}(\mathrm{W})$, and (3) combined curing of 7-day curing in saturated lime water then followed by curing in air at $27 \pm 2{ }^{\circ} \mathrm{C}, 50 \% \mathrm{RH}(\mathrm{WD})$ were used until testing ages. The compressive strength test was conducted at 3, 7, 28, and 90 days. The procedure for the compressive strength test was according to ASTM C109 (33). The shrinkage/expansion was monitored until 90 days. The procedure for the shrinkage/ expansion measurements were in accordance to ASTM C596 (34). 
The pieces of paste samples were soaked in alcohol to stop hydration and used for microstructural examinations by JSM-6390LV scanning electron microscope (SEM) and BRUKER, D2 PHASERX-Ray Diffractometer X-ray powder diffraction (XRD).

\section{RESULTS AND DISCUSSIONS}

\subsection{Workability}

The slump flow of mortar specimens was controlled by the SP additive to be $195 \pm 5 \mathrm{~mm}$ as shown in Table 2. With same W/B, the SFC mortars needed lower SP dosages than the OPC mortars, especially for those with the low W/B. The flowability was improved as the FFA increased. Such behavior could result from the optimized particle distribution of the SFC mortars. In addition, the OPC cement particles, normally, require more water or SP to produce certain workability because the flocs of cement particles trap some mixing water. On the other hand, the spherical FFA particles as additive in the SFC cement could significantly reduce the friction between the particles and lead to the higher flowability.

\subsection{Compressive strength}

The mean value and standard deviation for compressive strengths of three mortar specimens are shown in Table 3 where the mean values are shown in Figures 2-4. As can be seen in Table 3, the standard deviation of the mortars was in ranges of 0.510-1.961 MPa. The W/B, curing condition, and FFA additive significantly affected the compressive strengths of the SFC mortars. Figure 2 shows that the increase of compressive strength of SFC mortar with low FFA (10 wt.\%) was related to the increase of curing age and the decrease of $\mathrm{W} / \mathrm{B}$. The change of mechanical behavior of SFC mortars with 10 wt.\% FFA was also related to the curing regime. Based on Figure 3(a), the air curing was the best for the early compressive strength developments of the SFC mortars with 10 wt.\% FFA. However, to induce higher long-term compressive strengths, the combined curing was the best. The results showed that the curing in saturated lime water for 7 days was enough for the highest hydration of the SFC cement with $10 \mathrm{wt} . \% \mathrm{FFA}$, and the condensed microstructure of specimens was obtained as they were put in dry air due to the drying shrinkage The lower compressive strengths of the SFC mortars with $10 \mathrm{wt} . \%$ FFA cured in saturated lime water suggested that a little expansion was harmful to the condensed microstructure of specimens. The increase in FFA additive inversely affected the early compressive strengths of the SFC mortars (Figure 4). But, the compressive strengths of the SFC mortars with $30 \mathrm{wt} . \%$ FFA were similar to those of the low FFA mortars (with $10 \mathrm{wt} . \% \mathrm{FA}$ ) at ages longer than 7 days. The increase of FFA additive up to $50 \mathrm{wt} . \%$ inversely affected the compressive strengths of the SFC mortars at both early and later ages. Such results could be explained by the stability of FFA particles in a low alkaline environment provided by CFA.

Compared to the OPC mortars, the SFC mortars with low FFA (10 wt.\%) and high or medium W/B (0.4-0.35) had lower compressive strengths regardless of age and curing regime. However, after the ages of 7 days, the SFC mortars with 10 wt. \% FFA had high compressive strengths with the low W/B of 0.3 (Figure 2). The hydration of the SFC cement was slower than that of the OPC, thereby leading to the lower compressive strengths of SFC mortars at early ages. In this study, however, the optimum proportion of SFC mortars that had compressive strengths at the age of 3 days up to $92 \%$ of those of OPC mortars was the F10C15L30 mix (10 wt.\% of FFA and 15 wt. $\%$ of CFA with W/B of 0.3 ). Moreover, the hydration of the SFC cement needed lower water than that of the OPC. When compared at the equivalent compressive strengths, the W/B of the SFC mortars was lower than that of OPC mortars. For example, at the ages of 3, 7, 28, and 90 days, the compressive strengths of the OPC mortars with W/B of 0.4 were $46.3,51.1,63.2$, and $66.5 \mathrm{MPa}$, respectively, and the compressive strengths of the SFC mortars with $10 \mathrm{wt} . \%$ FFA and W/B of 0.35 were 46.1, 55.8, 62.5 , and $67.1 \mathrm{MPa}$, respectively. However, when a low W/B of 0.3 was used, the SFC cement with $10 \mathrm{wt} . \%$ FFA had enough water for hydration, leading to compressive strengths higher than those of the OPC mortars after the ages of 7 days (Figure 2).

\subsection{Shrinkage/expansion}

The shrinkage/expansion of mortars and pastes is shown in Figures 5-7. The shrinkage/expansion of the SFC mortars was affected by the W/B, curing condition, and FFA additive. The increase of W/B resulted in the increase of drying shrinkage and decrease of expansion when air and water curing were applied, respectively (see Figure 5). In the air, the higher drying shrinkage of the SFC mortars was induced by water loss rather than by autogenous drying shrinkage. In the water, the ceased evaporation of internal pore water and the more expansive AFt formation inside the specimens, as shown in -Figs. 8 and 9, induced the expansion. Generally, the mortars with lower W/B have more condensed microstructures than those with higher W/B. Thus, when the specimens are cured in water, the expansive AFt crystals induce the SFC mortars with lower W/B higher expansions than those of the SFC mortars with higher W/B. The combined curing led to the intermediate result. The specimens expanded when immersed in water or shrank when 
TABLE 3. Compressive strengths of three specimens for SFC and OPC mortars ( $\mathrm{MPa})$

\begin{tabular}{|c|c|c|c|c|c|c|}
\hline Mixes & days & S1 & S2 & S3 & mean & SD \\
\hline \multicolumn{7}{|l|}{ Air curing } \\
\hline \multirow[t]{4}{*}{ F10C15L30 } & 3 & 60.2 & 62.9 & 64.1 & 62.4 & 1.412 \\
\hline & 7 & 72.4 & 73.9 & 75.7 & 74.0 & 1.168 \\
\hline & 28 & 83.9 & 85.9 & 86.7 & 85.5 & 1.020 \\
\hline & 90 & 85.4 & 86.8 & 85.8 & 86.0 & 0.510 \\
\hline \multirow[t]{4}{*}{ F10C15L35 } & 3 & 44.9 & 47.2 & 48.6 & 46.9 & 1.321 \\
\hline & 7 & 57.1 & 56.1 & 54.5 & 55.9 & 0.927 \\
\hline & 28 & 64.1 & 62.7 & 64.3 & 63.7 & 0.616 \\
\hline & 90 & 64.0 & 64.2 & 65.9 & 64.7 & 0.738 \\
\hline \multirow[t]{4}{*}{ F10C15L40 } & 3 & 38.1 & 35.1 & 36.9 & 36.7 & 1.068 \\
\hline & 7 & 45.2 & 44.9 & 47.9 & 46.0 & 1.168 \\
\hline & 28 & 54.2 & 50.8 & 55.5 & 53.5 & 1.716 \\
\hline & 90 & 54.3 & 53.3 & 57.4 & 55.0 & 1.512 \\
\hline \multirow[t]{4}{*}{ F30C15L35 } & 3 & 38.4 & 39.8 & 42.4 & 40.2 & 1.435 \\
\hline & 7 & 53.1 & 52.8 & 55.5 & 53.8 & 1.046 \\
\hline & 28 & 59.7 & 61.7 & 63.1 & 61.5 & 1.208 \\
\hline & 90 & 64.8 & 68.1 & 65.7 & 66.2 & 1.206 \\
\hline \multirow[t]{4}{*}{ F50C15L35 } & 3 & 26.6 & 28.0 & 26.1 & 26.9 & 0.696 \\
\hline & 7 & 40.9 & 44.2 & 41.8 & 42.3 & 1.206 \\
\hline & 28 & 53.5 & 55.2 & 55.7 & 54.8 & 0.815 \\
\hline & 90 & 53.9 & 58.0 & 57.0 & 56.3 & 1.512 \\
\hline \multirow[t]{4}{*}{ OPCL30 } & 3 & 66.9 & 70.8 & 65.7 & 67.8 & 1.885 \\
\hline & 7 & 67.8 & 71.8 & 70.1 & 69.9 & 1.420 \\
\hline & 28 & 77.8 & 80.0 & 78.3 & 78.7 & 0.815 \\
\hline & 90 & 81.9 & 79.8 & 82.5 & 81.4 & 1.002 \\
\hline \multirow[t]{4}{*}{ OPCL35 } & 3 & 64.1 & 61.1 & 62.0 & 62.4 & 1.089 \\
\hline & 7 & 67.2 & 69.2 & 69.4 & 68.6 & 0.860 \\
\hline & 28 & 71.4 & 74.8 & 73.7 & 73.3 & 1.227 \\
\hline & 90 & 71.7 & 76.4 & 76.6 & 74.9 & 1.961 \\
\hline \multirow[t]{4}{*}{ OPCL40 } & 3 & 44.0 & 47.2 & 47.7 & 46.3 & 1.420 \\
\hline & 7 & 50.2 & 53.6 & 49.5 & 51.1 & 1.551 \\
\hline & 28 & 61.7 & 65.1 & 62.8 & 63.2 & 1.227 \\
\hline & 90 & 64.2 & 67.1 & 68.2 & 66.5 & 1.461 \\
\hline \multicolumn{7}{|l|}{ Water curing } \\
\hline \multirow[t]{4}{*}{ F10C15L35 } & 3 & 42.7 & 42.9 & 44.3 & 43.3 & 0.616 \\
\hline & 7 & 49.9 & 50.8 & 53.2 & 51.3 & 1.551 \\
\hline & 28 & 59.1 & 58.4 & 62.5 & 60.0 & 1.551 \\
\hline & 90 & 61.0 & 62.1 & 65.6 & 62.9 & 1.699 \\
\hline \multirow[t]{4}{*}{ OPCL35 } & 3 & 59.9 & 62.8 & 62.1 & 61.6 & 1.070 \\
\hline & 7 & 68.0 & 67.8 & 70.0 & 68.6 & 0.860 \\
\hline & 28 & 76.2 & 80.1 & 79.8 & 78.7 & 1.535 \\
\hline & 90 & 81.6 & 84.5 & 86.2 & 84.1 & 1.645 \\
\hline \multicolumn{7}{|c|}{ Combined curing } \\
\hline \multirow[t]{4}{*}{ F10C15L35 } & 3 & 42.7 & 42.9 & 44.3 & 43.3 & 0.616 \\
\hline & 7 & 49.7 & 51.1 & 51.6 & 50.8 & 0.696 \\
\hline & 28 & 63.8 & 64.2 & 68.5 & 65.5 & 1.843 \\
\hline & 90 & 69.1 & 74.0 & 70.2 & 71.1 & 1.818 \\
\hline
\end{tabular}

TABle 3. (Continued)

\begin{tabular}{llrrrrr}
\hline Mixes & days & S1 & S2 & S3 & mean & SD \\
\hline OPCL35 & 3 & 59.9 & 62.8 & 62.1 & 61.6 & 1.070 \\
& 7 & 67.8 & 70.0 & 68.0 & 68.6 & 0.860 \\
& 28 & 81.2 & 84.3 & 83.8 & 83.1 & 1.177 \\
& 90 & 86.1 & 81.8 & 83.2 & 83.7 & 1.551 \\
\hline
\end{tabular}

$\mathrm{S}=$ sample

$\mathrm{SD}=$ standard deviation

immersed in air (Figure 6). However, the SFC mortars cured in dry air $(50 \% \mathrm{RH})$ had higher shrinkage than those cured in air with higher RH $(65 \%)$, as shown in Figures 5, 6. Such results were related to the high compressive strengths of the SFC mortars cured in combined curing condition after the ages of 7 days (Figure 3). The increase of FFA additive resulted in the increase of shrinkage/expansion of the mortar prism regardless of the curing condition (i.e. curing in saturated lime water or air), as shown in Figure 7. This observation did not clearly show a negative effect of FFA additive on the shrinkage/ expansion of the SFC mortars. Because the FFA has the lower gravity than that of slag, the increase of FFA additive in the SFC mortars leads to the increased volume of pastes. Therefore, with a constant weight ratio of aggregate (i.e. sand) to paste, the volume ratio of paste to aggregate increased with the increase of FFA additive. Moreover, the shrinkage/ expansion of mortars has been mostly affected by the volume changes of pastes. As a result, high FFA additive increased the shrinkage/expansion of the SFC mortars. However, it can be confirmed that, if the volume ratio of sand to paste remains constant, the FFA additive significantly contributes to the reduced shrinkage/expansion of the SFC mortars/concretes because of the volume stability of FFA particles and the increase in AFt crystals (35). Therefore, to exactly understand the effects of different pozzolanic materials such as FFA on the properties of SFC mortars/concretes, the design method to obtain the optimal volumetric ratio of the materials is necessary. In this investigation, the FFA additive showed the negative effect on the shrinkage/ expansion of SFC mortars but the positive effect on the drying shrinkage of SFC pastes (Figure 7).

A comparison between the SFC and OPC mortars with 10 wt.\% FFA in Figure 5 shows that the drying shrinkage of the SFC mortars was lower than that of the OPC mortars when high or low W/B (0.4 or 0.3$)$ was used. The expansive AFt formation in the SFC mortars at W/B of 0.4 significantly reduced the drying shrinkage of specimens. Moreover, the decreased water demand for hydration and the increased AFt formation induced the lowest drying shrinkage of the SFC mortars at W/B of 0.3 . On the other hand, the drying shrinkage 

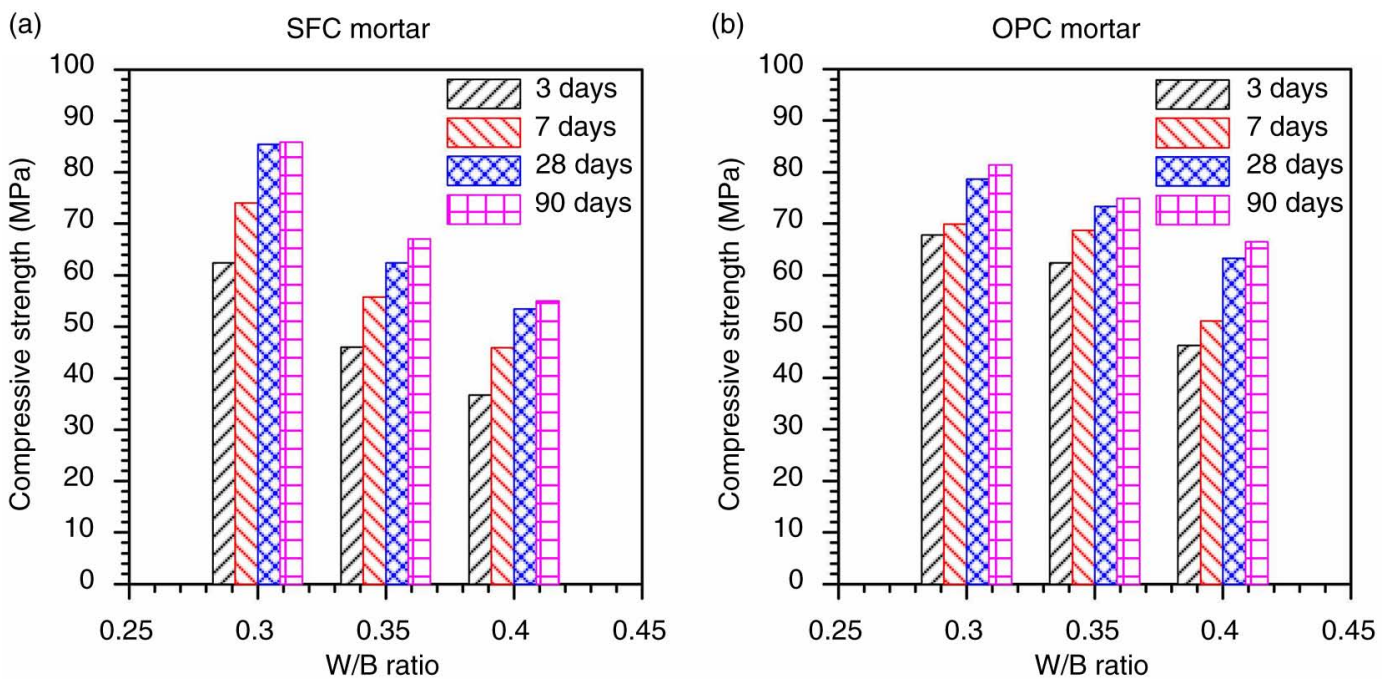

FIGURE 2. Effect of W/B ratio on the compressive strengths of (a): SFC mortars with FFA/slag=10/90, cured in air at $27{ }^{\circ} \mathrm{C}$ and $65 \% \mathrm{RH}$ and (b) OPC mortars, cured in air at $27{ }^{\circ} \mathrm{C}$ and $65 \% \mathrm{RH}$.
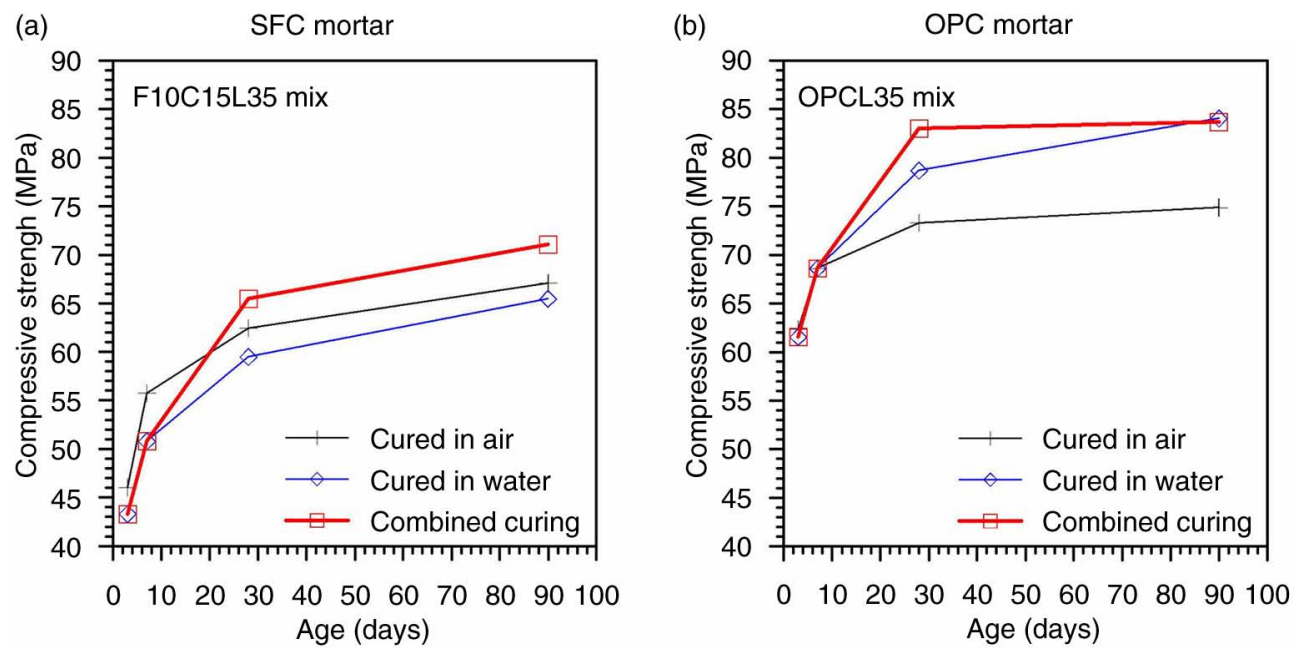

FIGURE 3. Effect of curing condition on compressive strength of (a) SFC mortars with FF A/slag=10/90 and (b) OPC mortars.

of the OPC mortars at W/B of 0.3 mostly resulted from the autogenous drying shrinkage because of the shortage of water for hydration. However, the OPC mortars at medium W/B (0.35) had enough water for hydration so that the drying shrinkage was reduced by both autogenous drying shrinkage and water loss. They had lower drying shrinkage than that of the SFC mortars at W/B of 0.35 (Figure 5(a)). In saturated lime water, the SFC mortars illustrated the lower expansion than that of OPC mortars when the high or medium W/B ( 0.4 or 0.35 ) was used. Such result could be attributed to the fact that the OPC mortars at high or medium W/B had more condensed microstructures than those of the SFC mortars at equivalent W/B.
When the expansive AFt crystals were formed, the mortars with more condensed microstructure had higher expansion as cured in water. Such results can be also explained by the different roles of AFt formation in the OPC and the SFC cements. Based on the results in Figure 5, the AFt formation essentially induced the expansion of the OPC mortars, and, however, the AFt formation in the SFC cement filled the micropores. On the other hand, the expansion of the SFC mortars at low W/B (0.3) was slightly higher than that of the OPC mortars with equivalent W/B. Such result confirmed that the SFC mortars with low W/B illustrated the more condensed microstructure than those of OPC mortars with the same W/B (Figure 2). 


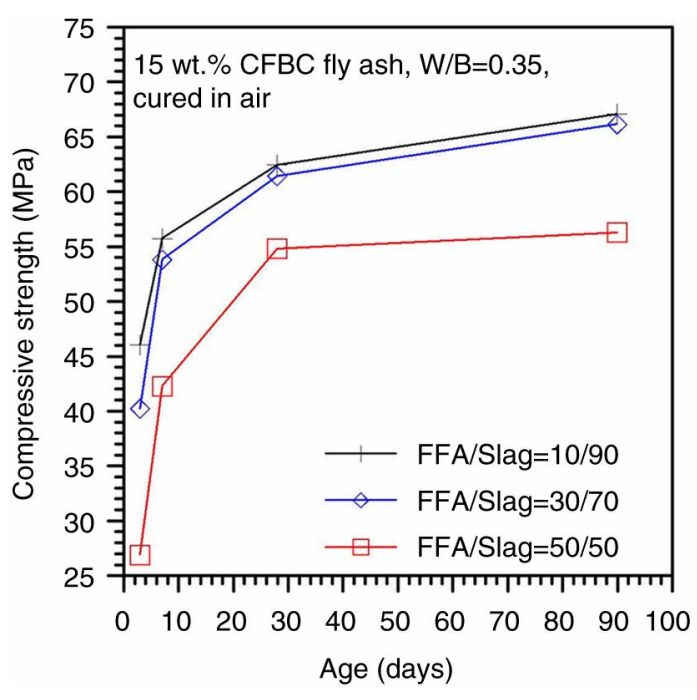

FIGURE 4. Effect of FFA amount on the compressive strengths of mortars with different fly ash contents.

\subsection{Microstructural analyses}

The hydration products and the hydration mechanism of the SFC cement could be relatively described based on the microstructural examination by SEM (Figure 8) and XRD (Figure 9). The SEM micrographs show that, at early ages, the main hydration products were the ettringite $(\mathrm{AFt})$ crystals and amorphous gels, such as the calcium silicate hydrate (C-S-H) or the calcium aluminum silicate hydrate (C-A-S-H) $(26,36-38)$. In this study, the AFt formation in the SFC cement likely complies with both Type I and Type II AFt crystals, as described by Mehta (39). These Type I and Type II AFt crystals were also detected in Figure 8(b) and
Figure 8(a), respectively. The early AFt formation detected in Figure 8(a) showed that, the FFA in the SFC cement was not only acted as the fillers but also the participants in the hydration. According to some authors (26), the dissolution of FFA particles could result from the increase in hydration heat of the slag. The early AFt, as formed in the mixture with the optimum ingredients, significantly increased the mechanical properties of the SFC cement because of the refined micropores by the increase of volume of these AFt crystals. With the increase in curing time, the increase in hydration of slag and/or FFA led to dissolved alkaline metals, such as sodium $(\mathrm{Na})$ or potassium (K), and increase in the $\mathrm{pH}$ value. Such result could induce the changes of partial morphology from AFt crystals to the mono-sulfate (AFm) phases (40) (Figure 8(b)).

The XRD patterns of pastes shown in Figure 9 clarified the crystalline hydration products shown in the SEM images. The disappearances of the portlandite, anhydrite, and lime peaks of the CFA, the reduced intensities of the mullite and quartz peaks of the FFA, and the appearances of the new hump and peaks in the specimens were the evidences of the dissolution of the raw materials. The hump at approximate $30^{\circ}$ in $2 \theta$ occurred at both early and later ages, suggesting the amorphous $\mathrm{C}-\mathrm{S}-\mathrm{H} / \mathrm{C}-\mathrm{A}-\mathrm{S}-\mathrm{H}$ gels. In addition, the sharp peaks of the AFt crystals were observed obviously at all days. In this study, the higher amplitudes of AFt peaks were observed in case of sample cured in water suggesting the more AFt formation could be precipitated due to the richness of propagating water from curing environment. Such expansive AFt formation induced the expansion of the specimens immersed in water as can be seen in Figures 5(b), (6), and 7(a). The condensed microstructure of the SFC paste with long curing
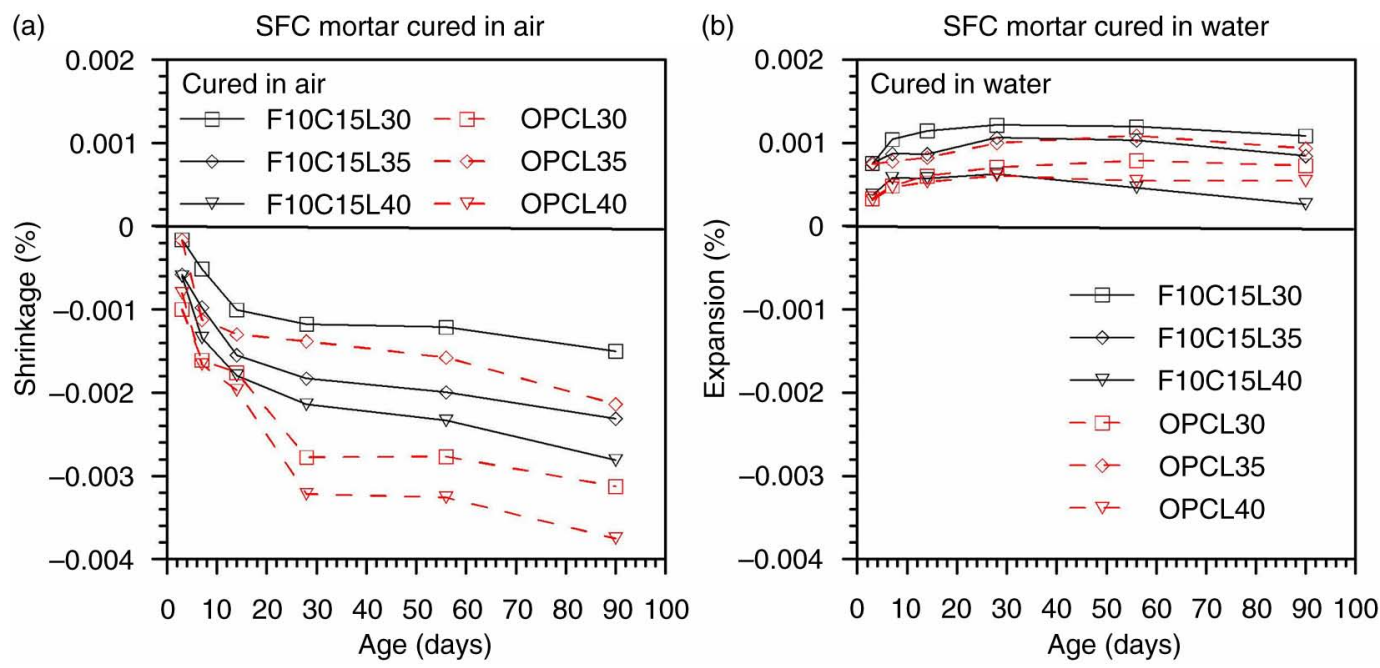

FIGURE 5. Effect of W/B ratio on the shrinkage/expansion of (a) SFC mortars with FFA/slag=10/90 and OPC mortars cured in the air and (b) SFC mortars with FFAslag=10/90 and OPC mortars cured in the saturated lime water. 


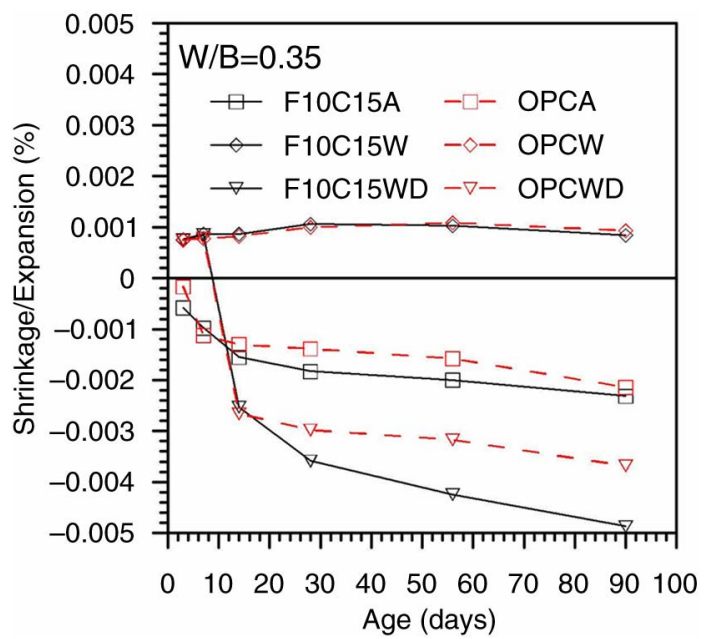

FIGURE 6. Effect of curing condition on tlie shrinkage/expansion of SFC mortars with FFA/slag $=10 / 90$ and OPC mortals.
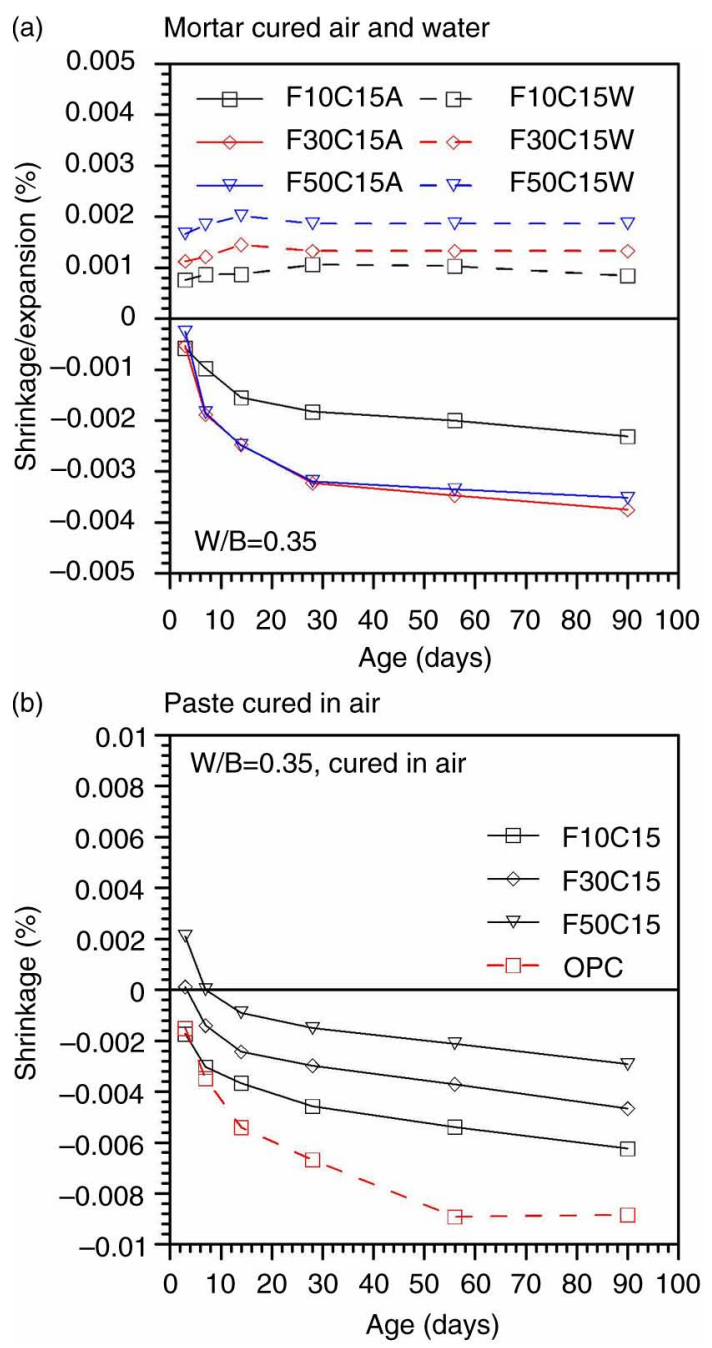

FIGURE 7. Effect of FFA amount on the shrinkage/expansion of (a) mortars and (b) pastes. (a) SFC paste at 3 days

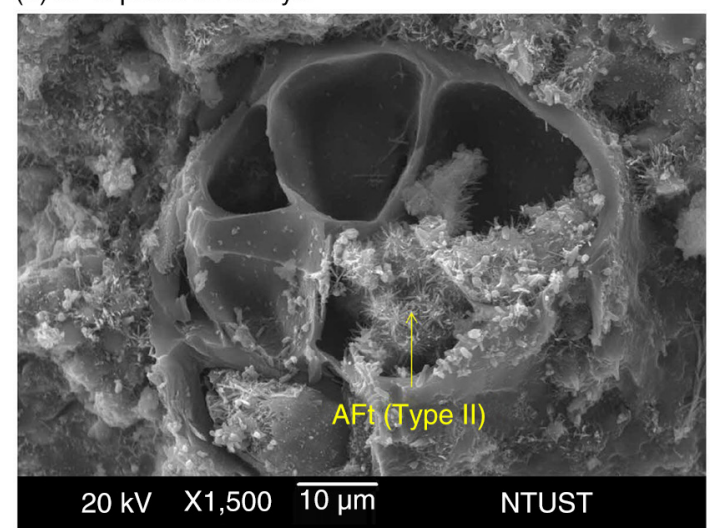

(b) SFC paste at 28 days

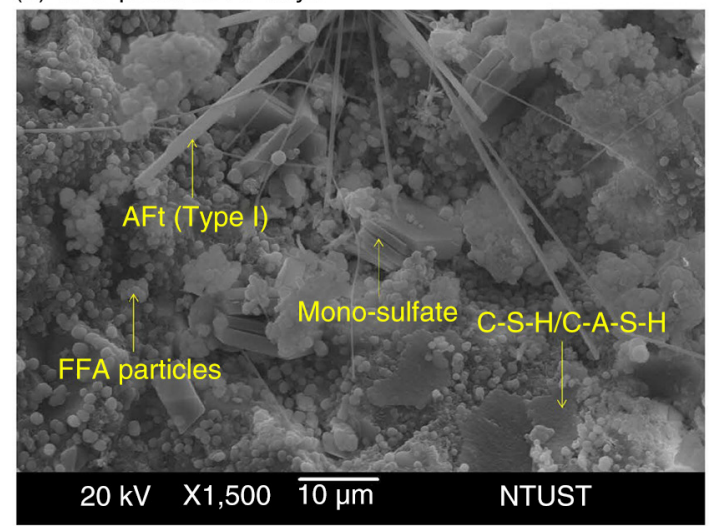

FIGURE 8. SEM images of SFC paste F30C15L35 made by $15 \mathrm{wt} . \% \mathrm{CFA}$, FFA/slag $=30 / 70$, and $\mathrm{W} / \mathrm{B}=0.35$ and cured in air at (a) 3 days with various magnification and (b) 28 days.

age was clarified by the increase in hump of gels. Moreover, the changes of AFt crystals to the AFm phases were proved by the reduction of AFt peaks at 28 days.

\section{CONCLUSIONS}

The satisfactory physical-chemical characteristics of the high performance pastes and mortars made by the SFC cement, comprised of ternary solid waste powders of ground granulated blast furnace slag, Class F fly ash (FFA) and CFBC fly ash (CFA), have been presented in this study. Such SFC cement could provide an alternative choice of binder for the construction of infrastructure due to its good engineering properties and shrinkage/expansion.

Similar to the OPC cement, the SFC cement had most gain of compressive strength after 3 to 7 days of curing. The W/B, curing condition and FFA additive were the main parameters affecting the engineering properties of the SFC mortars. With lower water consumption, the SFC mortars had lower compressive strengths than OPC mortars with high or medium W/B (0.4 or 0.35$)$. However, as a low W/B $(0.3)$ was 
(a)

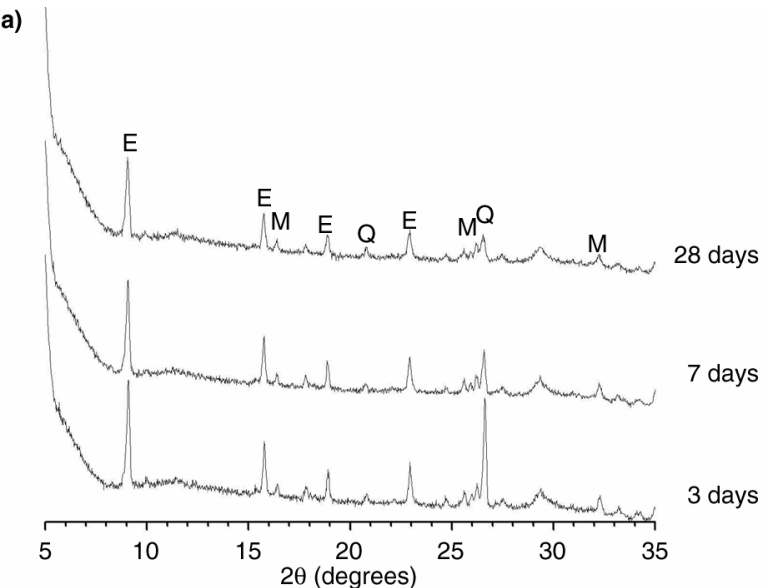

(b)

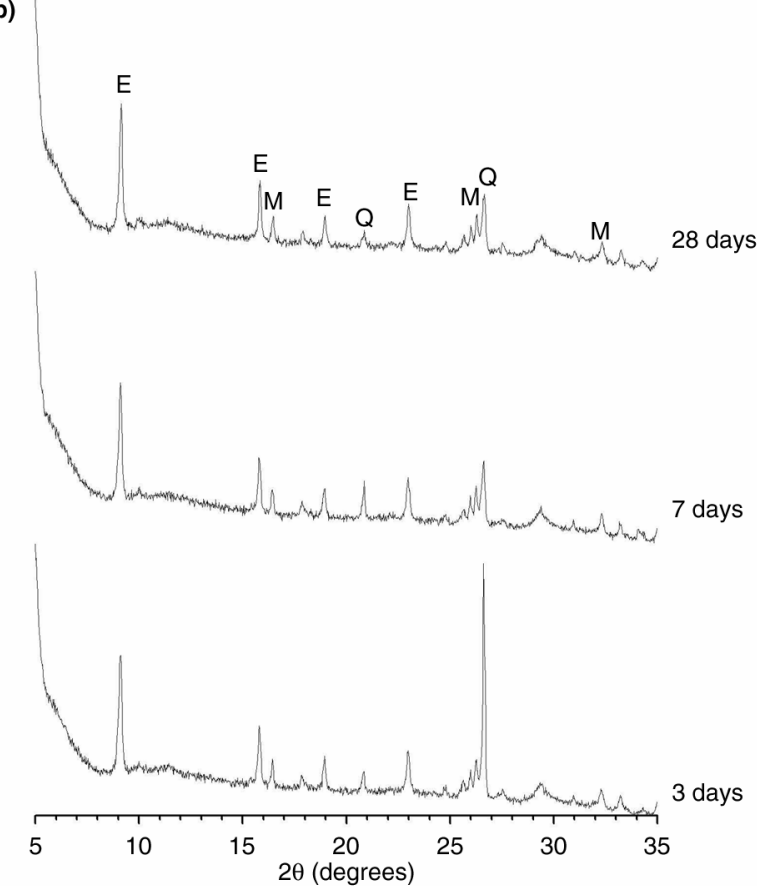

FIGURE 9. XRD patterns of SFC pastes (F30C15135) with 15 wt. $\%$ CFA and FFA/slag $=30 / 100$ at $\mathrm{W} / \mathrm{B}=0.35$ aired in (a) air and (b) water.

used, the SFC mortars could have comparable even higher compressive strengths with those of OPC mortars at all ages. The air curing and the combination of water curing followed by air curing were the preferable regimes for the SFC cement, but the water curing was better for the OPC. The increase of FFA up to $30 \mathrm{wt} . \%$, as partial replacement of the slag, delayed the compressive strength development of the SFC mortars at early ages but did not show a negative effect on the compressive strengths of the SFC mortars at later ages.

The shrinkage/expansion of the SFC mortars was mainly affected by W/B, curing condition, and FFA additive as well. The higher W/B led to higher drying shrinkage and the lower expansion. The FFA additive had negative effects on the shrinkage/expansion of the SFC mortars but showed benefits from reducing drying shrinkage of the SFC pastes. Through the results, a unit volume method has been proposed to design the durable composite materials, such as mortars and concretes.

The microstructural analyses by the scanning electron microscopy (SEM) and X-ray diffraction (XRD) showed that the main hydration products in the SFC cements are ettringite (AFt) and calcium silicate hydrate or calcium aluminum silicate hydrate (C-S-H or C-A-S-H). With the increase in hydration, the transformation of the AFt to the mono-sulfates occurred.

\section{ACKNOWLEDGEMENT}

The authors would like to acknowledge the financial aid from National Taiwan University of Science and Technology for completing this investigation.

\section{REFERENCES}

1. Anthony, E.J. (1995). Fluidized bed combustion of alternative solid fuels; status, successes and problems of the technology. Prog Energ Combust. 21 [3], 239-268. http:// dx.doi.org/10.1016/0360-1285(95)00005-3.

2. Anthony, E.J.; Granatstein, D.L. (2001). Sulfation phenomena in fluidized bed combustion systems. Prog Energ Combust. 27 [2], 215-236. http://dx.doi.org/10.1016/S03601285(00)00021-6.

3. Sheng, G.; Li, Q.; Zhai, J. (2012). Investigation on the hydration of CFBC fly ash. Fuel, 98, 61-66. http://dx.doi. org/10.1016/j.fuel.2012.02.008.

4. Fernández-Jiménez, A.; Puertas, F. (1997). Influence of the activator concentration on the kinetics of the alkaline activation process of a blastfurnace slag. Mater. Construcc, 47 [246], 31-42. http://dx.doi.org/10.3989/mc.1997.v47.i246.505.

5. Ortega, J.; Sánchez, I.; Climent, M. (2013). Influence of different curing conditions on the pore structure and the early age properties of mortars with fly ash and blast-furnace slag. Mater. Construcc, 63 [310], 219-234. http://dx.doi.org/ 10.3989/mc.2012.06111.

6. Sanjuán, M.; Piñeiro, A.; Rodríguez, O. (2011). Ground granulated blast furnace slag efficiency coefficient (k value) in concrete. Applications and limits. Mater. Construcc, 61 [302], 303-313. http://dx.doi.org/10.3989/mc.2011.60410.

7. Rodríguez, E.; Bernal, S.; Mejía de Gutiérrez, R.; Puertas, F. (2008). Alternative concrete based on alkali-activated slag. Mater. Construcc. 58 [291], 53-67. http://dx.doi.org/10.3989/ mc.2008.v58.i291.104

8. Fernández-Jiménez, A.; Puertas, F. (2001). Alkaline activated slag cements. Determination of reaction degree. Mater. Construcc, 51 [261], 53-66. http://dx.doi.org/10.3989/mc. 2001.v51.i261.380.

9. García Medina, L.; Orrantia Borunda, E.; Aquilar Elguézabal, A. (2006). Use of copper slag in the manufacture of Portland cement. Mater. Construcc, 56 [281], 31-40. http://dx.doi.org/10.3989/mc.2006.v56.i281.90.

10. Bijen, J. (1996). Benefits of slag and fly ash. Construc. Build. Mat. 10 [5], 309-314. http://dx.doi.org/10.1016/09500618(95)00014-3.

11. Chi, M.; Huang, R. (2013). Binding mechanism and properties of alkali-activated fly ash/slag mortars. Construc. Build. Mat 40, 291-298. http://dx.doi.org/10.1016/j. conbuildmat.2012.11.003.

12. Duran Atis, C. (2005). Strength properties of high-volume fly ash roller compacted and workable concrete, and influence of curing condition. Cem. Concr. Res, 35 [6], 1112-1121. http://dx.doi.org/10.1016/j.cemconres.2004.07.037. 
13. Nath, S.K.; Kumar, S. (2013). Influence of iron making slags on strength and microstructure of fly ash geopolymer. Construc. Build. Mat 38, 924-930. http://dx.doi.org/10.1016/j. conbuildmat.2012.09.070.

14. Rattanasak, U.; Pankhet, K.; Chindaprasirt, P. (2011). Effect of chemical admixtures on properties of high-calcium fly ash geopolymer. Int J Miner Metall Mater, 18 [3], 364-369. http://dx.doi.org/10.1007/s12613-011-0448-3.

15. Shariq, M.; Prasad, J.; Masood, A. (2013). Studies in ultrasonic pulse velocity of concrete containing GGBFS. Construc. Build. Mat 40 [0], 944-950. http://dx.doi.org/10.1016/j. conbuildmat.2012.11.070.

16. Bijen, J.; Niël, E. (1981). Supersulphated cement from blastfurnace slag and chemical gypsum available in the Netherlands and neighbouring countries. Cem. Concr. Res, 11 [3], 307-322. http://dx.doi.org/10.1016/0008-8846(81)90104-6.

17. Dutta, D.K.; Borthakur, P.C. (1990). Activation of low lime high alumina granulated blast furnace slag by anhydrite. Cem. Concr. Res, 20 [5], 711-722. http://dx.doi.org/10.1016/ 0008-8846(90)90005-I.

18. Gruskovnjak, A.; Lothenbach, B.; Winnefeld, F.; Figi, R.; Ko, S.C.; Adler, M.; Mäder, U. (2008). Hydration mechanisms of super sulphated slag cement. Cem. Concr. Res, 38 [7], 983-992. http://dx.doi.org/10.1016/j.cemconres.2008.03.004.

19. Ma, W.; Liu, C.; Brown, P.W.; Komarneni, S. (1995). Pore structures of fly ashes activated by $\mathrm{Ca}(\mathrm{OH})_{2}$ and $\mathrm{CaSO}_{4} \cdot 2 \mathrm{H}_{2} \mathrm{O}$. Cem. Concr. Res, 25 [2], 417-425. http://dx.doi.org/10.1016/ 0008-8846(95)00027-5.

20. Midgley, H.G.; Pettifer, K. (1971). The micro structure of hydrated super sulphated cement. Cem. Concr. Res, 1 [1], 101-104. http://dx.doi.org/10.1016/0008-8846(71)90086-X.

21. Shi, C. (1998). Pozzolanic Reaction and Microstructure of Chemical Activated Lime-Fly Ash Pastes. ACI Materials Journal, 95 [5], 537-545.

22. Singh, M.; Garg, M. (2002). Calcium sulfate hemihydrate activated low heat sulfate resistant cement. Construc. Build. Mat 16 [3], 181-186. http://dx.doi.org/10.1016/S0950-0618 (01)00026-5

23. Sivapullaiah, P.; Moghal, A. (2011). Role of Gypsum in the Strength Development of Fly Ashes with Lime. J Mater Civil Eng. 23 [2], 197-206. http://dx.doi.org/10.1061/(ASCE) MT.1943-5533.0000158.

24. Rust, D.; Rathbone,R.; Mahboub, K.C.; Robl, T. (2012). Formulating Low-Energy Cement Products. J Mater Civil Eng. 24 [9], 1125-1131. http://dx.doi.org/10.1061/(asce)mt. 1943-5533.0000456.

25. Salain, I.M.A.K.; Clastres, P.; Bursi, J.M.; Pellissier, C. (2001). Circulating Fluidized Bed Combustion Ashes as an Activator of Ground Vitrified Blast Furnace Slag. Special Publication, 202, 225-244.

26. Zhao, F.-Q.; Ni, W.; Wang, H.-J.; Liu, H.-J. (2007). Activated fly ash/slag blended cement. Resour Conserv Recy. 52 [2], 303-313. http://dx.doi.org/10.1016/j.resconrec.2007.04.002.
27. Zhong, S.; Ni, K.; Li, J. (2012). Properties of mortars made by uncalcined FGD gypsum-fly ash-ground granulated blast furnace slag composite binder. Waste Manage 32 [7], 1468-1472. http://dx.doi.org/10.1016/j.wasman.2012.02.014.

28. Singh, M.; Garg, M. (2007). Durability of cementing binders based on fly ash and other wastes. Construc. Build. Mat 21 [11], 2012-2016. http://dx.doi.org/10.1016/j.conbuildmat. 2006.05 .032

29. ASTMC150-12. Standard Specification for Portland Cement. ASTM Book of Standards.

30. Sheng, G.; Zhai, J.; Li, Q.; Li, F. (2007). Utilization of fly ash coming from a CFBC boiler co-firing coal and petroleum coke in Portland cement. Fuel, 86 [16], 2625-2631. http://dx.doi.org/10.1016/j.fuel.2007.02.018.

31. Wang, B.; Song, Y. (2013). Methods for the control of volume stability of sulfur-rich $\mathrm{CFBC}$ ash cementitious systems. Mag Concrete Res. 65 [19], 1168-1172. http:// dx.doi.org/10.1680/macr.13.00070.

32. ASTMC1437-13. Standard Test Method for Flow of Hydraulic Cement Mortar. ASTM Book of Standards.

33. ASTMC109-13. Standard Test Method for Compressive Strength of Hydraulic Cement Mortars (Using 2-in. or [50-mm] Cube Specimens). ASTM Book of Standards.

34. ASTMC596-09. Standard Test Method for Drying Shrinkage of Mortar Containing Hydraulic Cement. ASTM Book of Standards.

35. Aimin, X.; Sarkar, S.L. (1991). Microstructural study of gypsum activated fly ash hydration in cement paste. Cem. Concr. Res 21 [6], 1137-1147. http://dx.doi.org/10.1016/ 0008-8846(91)90074-R

36. Andersen, M.D.; Jakobsen, H.J.; Skibsted, J. (2004). Characterization of white Portland cement hydration and the C-S-H structure in the presence of sodium aluminate by $27 \mathrm{Al}$ and 29Si MAS NMR spectroscopy. Cem. Concr. Res, 34 [5], 857-868. http://dx.doi.org/10.1016/j.cemconres.2003.10.009.

37. Pardal, X.; Pochard, I.; Nonat, A. (2009). Experimental study of Si-Al substitution in calcium-silicate-hydrate $(\mathrm{C}-\mathrm{S}-\mathrm{H})$ prepared under equilibrium conditions. Cem. Concr. Res, 39 [8], 637-643. http://dx.doi.org/10.1016/j.cemconres.2009. 05.001 .

38. Thomas, J.J.; Rothstein, D.; Jennings, H.M.; Christensen, B.J. (2003). Effect of hydration temperature on the solubility behavior of $\mathrm{Ca}-, \mathrm{S}-, \mathrm{Al}-$, and Si-bearing solid phases in Portland cement pastes. Cem. Concr. Res, 33 [12], 2037-2047. http://dx.doi.org/10.1016/S0008-8846(03)00224-2.

39. Mehta, P.K. (1983). Mechanism of sulfate attack on portland cement concrete-Another look. Cem. Concr. Res. 13 [3], 401-406. http://dx.doi.org/10.1016/0008-8846(83)90040-6.

40. Donatello, S.; Fernández-Jimenez, A.; Palomo, A. (2013). Very High Volume Fly Ash Cements. Early Age Hydration Study Using $\mathrm{Na}_{2} \mathrm{SO}_{4}$ as an Activator. J. Am. Ceram. Soc. 96 [3], 900-906. http://dx.doi.org/10.1111/jace.12178. 